\title{
The Influence of Condition of Minibus Taxis, Compliance with Road Rules on Quality of Service and Commuter Satisfaction in Harrismith, South Africa
}

Richard Chinomona

\author{
Department of Logistics, Vaal University of Technology \\ Private Bag X021, Vanderbijlpark 1900, South Africa \\ E-mail:rchinos@hotmail.com
}

Tebogo Mofokeng

Vaal University of Technology, South Africa

David Pooe

Vaal University of Technology, South Africa

Doi:10.5901/mjss.2013.v4n14p319

\begin{abstract}
Despite the increasing awareness of the paramount importance of service quality on commuter satisfaction in the context of public transport, research efforts focused on the investigation of the role of condition of minibuses, compliance with road rules and service quality in fostering commuter satisfaction within minibus taxi service sector have largely remained scant, particularly in developing countries of Southern Africa. Therefore, the primary objective of this study is to fill this void. Three research hypotheses are posited and a sample data of 213 collected from the commuters in Harrismith, South Africa was used to empirically test the hypotheses. The results of this study show that, the condition of minibuses and compliance with road rules positively influences quality of service and commuter satisfaction in a significant way. Public transit implications of the findings are discussed and limitations as well as future research directions are indicated.
\end{abstract}

Keywords: Minibus condition, Road rules compliance, Quality of service, Commuter satisfaction.

\section{Introduction}

Public transportation plays a significant role in strengthening the economy of a country, facilitating livelihood as well as providing social welfare (Petzall, 1995; Redman, Friman, Garling \& Hartig, 2013). The minibus taxi service resides under this umbrella and it forms part of the core contributors to a country's wealth. Our society has become increasingly dependent on transportation (Aberg, 1998; Burns and Wilde, 1995; Olio, Ibeas \& Cecin, 2010). It is due to such dependency, that this study find it necessary to examine the role played by minibus taxis condition and their drivers' compliance with road rules on the quality of service rendered to the general public. Eventually, the study seeks to enquire if the quality of service offered by the minibus taxis meets the commuters' expectation hence their satisfaction. While there has been an upsurge in various modes of public transport in South Africa, it is noticeable that minibus taxis have remained the popular means of public transport utilized by many South Africans, especially for short destinations (Olio, Ibeas \& Cecin, 2010). What is worrisome is that, generally there has been an increase in road accidents associated with minibus taxis in the past few years - which according to some analysts is attributed to the state of the minibus taxis condition or lack of compliance to road rules (Olio, Ibeas \& Cecin, 2010; Redman, Friman, Garling \& Hartig, 2013). It is against this mainstay that the current study is found imperative.

There is an adage now popularly acknowledged by those in the business fraternity as indicative of the truth - "the client is the king". It is argued in the extant literature that for any viable business to be sustainable in the long term, it should be premised on constant customer satisfaction (Ramasubbu, Mithas \& Krishnan, 2008; Fornel, Johnson, Anderson, Cha \& Bryant, 1996; Chinomona, 2013). As a result, research related to customer satisfaction, especially in the marketing discipline has been on the increasing side for decades (Bearden \& Teel, 1993; Fernandez-Bremaunts \& Ashmore, 1995; Vazquez, Bosque, Diaz \& Ruiz, 2001; Fornel, Mithas, Morgeson \& Krishnan, 2006; Tseng, 2009; 
Chinomona \& Ming-Sung Chen, (2013). Many antecedents of customer satisfaction seem to be noted in these literature and in the service sector, quality of service delivered appear to be one of the outstanding ones (Paquette, Cordeau \& Larporte, 2009; Chinomona \& Sandada, 2013). However, there is a noticeable dearth of similar studies focusing on public transport service sector (c.f. Redman, Friman, Garling \& Hartig, 2013). In particular, as a result of research deficit in this arena, the precursors to service quality in the public transport sector have remained unclear and less understood in the African context.

In order fill in this research void, the current study has three empirical objectives, that is:

1. to investigate the influence of condition of minibus taxis on quality of service experienced by commuters in Harrismith-South Africa

2. to investigate the influence of minibus taxis drivers' compliance with road rules on the quality of service experienced by commuter in Harrismith-South Africa and finally

3. to investigate the influence of quality of service rendered by minibus taxis on commuter satisfaction in Harrismth-South Africa

The remainder of this study is structured as follows: The following section presents literature review. Then next section provides the conceptual model and hypothesis development, and is followed by a section on research methodology. After that, a section involves data analysis follows and finally the last section provides a discussion of results, conclusion, and implication of the study as well as the limitations of the study.

\section{Literature Review}

\subsection{Condition of Omnibus Taxis}

According to Sekhoyane and Dugard (2001:14) one of the most pressuring transport related challenges facing the government of South Africa is to establish a minibus taxi industry that is safe, effective and reliable and that will contribute to growth and the country's economy. While some minibus taxi operations have not survived fines that were imposed or the confiscation of their vehicles, most have continued to expand their businesses (Ferreira, 2010). According to the White Paper on National Policy of 1996, sixteen seaters and larger vehicles should be allowed to operate as omnibus taxis. Permits were issued on merit provided that the vehicle adhered to road worthiness and safety requirements of inter alia, proper tyres and adequate lighting. In an effort to ensure that the omnibus taxis are in good condition, a recapitalization programme was initiated by the government in 1999 to replace ageing omnibus taxis fleet with new vehicles that are safer and more reliable. Condition refers to a mode or state of being. Although 'condition' appears to be unidimensional, authors seem to be discussing the construct in different context (Olvera, Plat \& Pochet, 2003; Petzall, 1995; Fernandez-Bremauntz \& Ashmore, 1995) and there appears to be no distinct definitions among them. However, condition of minibus taxis in this study is operationalized as a way of being that describes the minibus taxi.

\subsection{Quality of Service}

The importance of service quality is due to its ability to distinguish highly successful firms from those that are merely average (Lapierre, Filiatrault \& Perrein, 1996). Service companies are now preoccupied with quality because of the growing competition from globalization and as a result of the constant increase in customers' expectations and needs. (Paquette, Cordeau \& Laporte, 2009). In public transportation, services are typically operated with second-hand omnibus taxis ranging from 8-20 seater vehicles (Finn, 2008). Finn (2008) also reveals that vehicle conditions range from extremely poor to moderate and that in the initial stages as the omnibus taxi became established, operating standards, driver training, safety, discipline and customer service are often far below the basic level previously available in the bigbus service. However as disappointing as this may be, these omnibus taxis are important to people who do not have regular access to any form of motorized transport (Lucas, 2011). Perhaps, this is because it helps them in their ability to participate in key economic and social activities. Service quality is a comparison of expectation with performance. Research on service quality is divided according to the technical and the fundamental quality dimensions proposed by Gronroos (1984). Naik and Gantasala (2010) define service quality as the ability to perform promised service dependably and accurately. In this study, service quality is defined as conforming to standards above average in order to receive the most attractive returns. 


\subsection{Compliance with Road Rules}

Driving performance is affected by various factors which together determine its level of safety or risk (Rosenbloom \& Shahar, 2007). Peltzer and Renner (2003) point out that improper communication of taxi drivers with law enforcers possibly reflects high levels of risk. Taking behaviour among taxi drivers which is buffered by the enforcement of traffic regulations by the police, the taxi drivers' concern is that they are targeted by the police and law enforcers, while the police concerns are that taxi drivers ignore traffic laws more than the general population (Rosenbloom \& Shahar, 2007). Nonetheless, the negligent driving of taxi drivers cannot be justified. Buns and Wilde (1995) reported that taxi drivers were characterized by driving in excessive speeds and carelessly changing lanes. Compliance with traffic laws affects their own safety as well as their passengers and that of other road users (Rosenbloom \& Shahar, 2007). Compliance refers to the state or fact of according with or meeting rules or standards. Previous researchers tend to unintentionally avoid defining rule compliance but rather elaborate on the state, cause and the consequence of non-compliance (Aberg, 1998; Zhong, Zhou, Ma \& Jia, 2010; Tom \& Graine, 2011; Bjorklund \& Aberg, 2005; Rothengatter, 1991). In this study, the construct is defined as conforming to stipulations set in road traffic.

\subsection{Commuter Satisfaction}

Goodwin and lyons (2010) argued that citizens as commuters represent an invaluable source of information and that a good understanding of public perceptions, attitudes and experiences of the transport system is necessary for both democratic accountability and for developing effective public policy. The makers of psycho-physiological stress provide objective evidence that the community experiences are stressful (Wener, Evans \& Boately, 2005). Insufficient capacity and crowding is a major cause of stress among commuters who use public transport (Cantwell, Caulfield \& O'Mahony, 2009). If factors identified by Prioni and Hensher (2000) that make public transport attractive to users such as wait time, trip length, vehicle design, driver interaction were to exist, then surely the level of commuter satisfaction would increase, thereby reducing stress among commuters, hence improving people's way of life. Commuter satisfaction appears to be unidimensional with authors such as Eriksson, Friman and Garling (2013), defining the construct as 'travel happiness'. In this study the construct is operationalized as the commuter's content with travel by minibus taxis.

\section{Conceptual Model and Hypothesis Development}

Drawing from the extant literature on transport policy, transport research and safety research aforementioned, a conceptual model is developed in Figure 1. The model consists of four constructs, that is, two predictors - condition of minibuses and compliance with road rules, one mediator - quality of service, and one outcome variable - commuter satisfaction. Conceivably, the condition of omnibus taxis and compliance with road rules influences the quality of service which eventually also impact on commuter satisfaction. Detailed explanations of the associations between these constructs are provided in the hypotheses developed hereafter.

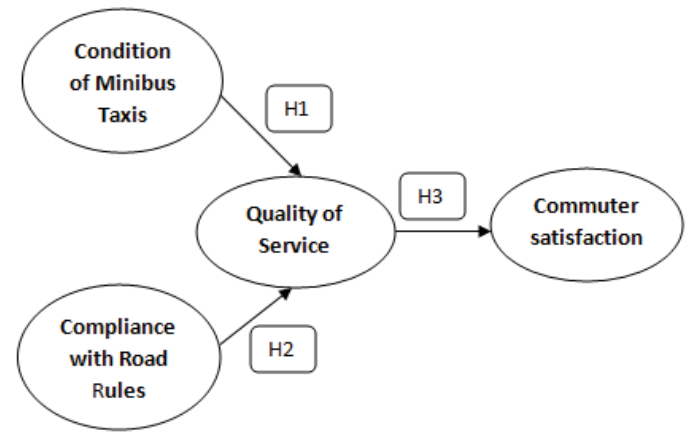

Figure 1: Conceptual Model

\subsection{Condition of Minibus Taxis and Quality of Service}

Service quality in the public transportation industries depends on factors such as conditions of safety for consumers in 
terms of roads, the commuting omnibus and other related factors. More so, the behavior of minibus taxis personnel are likely to contribute to overall service quality experienced by minibus taxis commuters. The manner in which the minibus taxis operators maintain their vehicles in order to be road worthy and the rapport that characterize the minibus taxis personnel interactions with the commuters are critical aspects of quality of service experienced by the commuters (Ramasubbu, Mithas and Krishnan, 2008). Therefore once the general conditions of the commuting omnibuses are according to government stipulated standards and also combined with better behavioral skills of personnel (minibus taxi officials), it is expected that commuters will derive better service quality from using omnibus taxis. Thus, based on such reasoning, this paper hypothesizes that: Harrismith.

H1: The condition of minibus taxi has a positive influence on quality of service experienced by commuters in

\subsection{Compliance with Road Rules and Quality of Service}

Given the increasing road carnage in South Africa and the high death rates resulting from road related accidents, drivers' compliance with road rules has become a cause of concern to commuters and the government law enforcement officials alike (Ramasubbu, Mithas and Krishnan, 2008). It is therefore submitted in the current study that the more law abiding the drivers of the minibus taxis are, the more the commuters are likely feel safe. Accordingly, the more the safety the commuters perceive, the better the quality of service experience. Thus, it can be hypothesized that:

H2: The compliance with road by minibus taxis drivers has a positive influence on quality of service experienced by commuters in Harrismith.

\subsection{Quality of Service Experienced and Commuters' Satisfaction}

There is growing evidence in the extant literature indicating that satisfaction is one of the recognized behavioral outcomes of quality of service (c.f. Chinomona \& Ming-Sung Chen, 2013). In the context of this study, it is expected that when commuters perceive the quality of service they receive from using minibus taxis as a means of transport to be up to their expected standards, then they are likely to be satisfied. On the contrary, poor service quality will lead to their dissatisfaction. It is therefore, posited that the higher the level of quality of service the commuters experience, the more satisfied they are likely to be - hence the following hypothesis:

H3: The quality of service experienced by the commuters has a positive influence on commuters' satisfaction in Harrismith.

\section{Research Methodology}

\subsection{Sample and data collection}

The data for this research was collected from Harrismith, a small town in the Free State Province of South Africa. The research sampling frame was Tshiame A and Tshiame B of Harrismith. The list of residents who were possible commuters was obtained from the Maluti-A-Phofung Municipality in Harrismith. Two teachers and a factory worker working in Tshiame A \& B in Harrismith respectively were recruited to distribute and collect the questionnaires. Appointments at the targeted schools factory were made on a face to face account. Of the total of 274 questionnaires distributed, 213 usable questionnaires were retrieved for the final data analysis, representing a response rate of 78 percent.

\subsection{Measurement Instrument and Questionnaire Design}

Research measures were operationalized on the basis of previous work. Proper modifications were made in order to fit the current research context and purpose. "Condition of omnibus taxis" measure used five-item scales while "quality of service" used a nine items all adapted from Gule (2009). "Compliance with road rules" used a six-item measure was adopted from Ferreira (2006) and "commuter satisfaction" used a five-item was adopted from Chinomona and Ming-Sung Chen, (2013). All the measurement items were measured on a five-point Likert-type scales that was anchored by $1=$ strongly disagree to $5=$ strongly agree to express the degree of agreement. Individual scale items are listed in Appendix 1. 


\subsection{Respondent Profile}

Table 1 presents the profile of the participants. The profile indicates that less than a half of the participants were males (40.8\%). More than two thirds of the participants were between 18-25 years old (70.4\%). Less than a quarter of participants were between $26-35$ years (11.3\%), 36-45 years (7.0\%) 46-45 years (10.3\%) and lastly those who were 56 years and above (9\%). Also two thirds of the participating employees were in high school or college (66.7\%) and the remaining were factory workers (8.5\%), teachers (18.3\%), shop assistants (2.8\%) and 3.8\% had other occupations. The study also indicated that less than two thirds (65.3\%) of the participants had matriculation as a qualification, $11.7 \%$ had certificates, $12.7 \%$ had diploma, $6.6 \%$ had a degree, $3.3 \%$ had a post-graduate qualifications and $5 \%$ had other qualifications.

Table 1: Sample Demographic Characteristics

\begin{tabular}{|c|c|c|}
\hline Gender & Frequency & Percentage \\
\hline Male & 87 & $40.8 \%$ \\
\hline Female & 126 & $59.2 \%$ \\
\hline Total & 213 & $100 \%$ \\
\hline Age & Frequency & Percentage \\
\hline $18-25$ & 150 & $70.4 \%$ \\
\hline $26-35$ & 24 & $11.3 \%$ \\
\hline $36-45$ & 15 & $7.0 \%$ \\
\hline $46-55$ & 22 & $10.3 \%$ \\
\hline 56 and above & 2 & $9 \%$ \\
\hline Total & 213 & $100 \%$ \\
\hline Occupation & Frequency & Percentage \\
\hline High school/college & 142 & $66.7 \%$ \\
\hline Factory worker & 18 & $8.5 \%$ \\
\hline Teacher & 39 & $18.3 \%$ \\
\hline Shop assistant & 6 & $2.8 \%$ \\
\hline Other & 8 & $3.8 \%$ \\
\hline Total & 213 & $100 \%$ \\
\hline Academic qualification & Frequency & Percentage \\
\hline Matriculation & 139 & $65.3 \%$ \\
\hline Certificate & 25 & $11.7 \%$ \\
\hline Diploma & 27 & $12.7 \%$ \\
\hline Degree & 14 & $6.6 \%$ \\
\hline Post-graduation & 1 & $3.3 \%$ \\
\hline Other & 7 & $5 \%$ \\
\hline Total & 213 & $100 \%$ \\
\hline
\end{tabular}

\section{Data Analysis}

In this study, structural equation modeling (SEM) approach using Smart PLS statistical software (Ringle, Wende and Will, 2005) was employed to test the hypotheses in the conceptual research model. Smart PLS is suitable for a small sample size and does not require normal distribution of the manifest variables (Chin, 1999). Since the current study sample size is relatively small (213), Smart PLS was found more appropriate and appropriate in achieving the purpose of the current study. As recommended by Anderson and Gerbing (1988), a two stage procedure to hypothesis testing using SEM is utilised in this study. Measurement model assessment is performed first by examining the convergent and discriminant validity of items and constructs respectively, before the testing of the hypothesised causal relationship between the research variables in the structural model.

\subsection{Measurement model}

To ensure convergent validity, the researcher checked if items loaded on their respective (a priori) constructs with loadings greater than 0.6 , while discriminant validity was checked by ensuring that there was no significant inter-research 
variables cross-loadings (Chin, 1998). As can be seen in Table 2, all items have loadings greater than 0.6 , with no crossloadings greater than 0.850 , while t-statistics derived from bootstrapping (213 resamples) suggest all loadings are significant at pb0.001. As such, this confirms that all the measurement items mostly converged well on their respective constructs and therefore are acceptable measures.

Table 2: Accuracy Analysis Statistics

\begin{tabular}{|c|c|c|c|c|c|c|c|c|}
\hline \multicolumn{2}{|c|}{$\begin{array}{l}\text { Research } \\
\text { Construct }\end{array}$} & $\begin{array}{l}\text { LV Index } \\
\text { Value }\end{array}$ & $\begin{array}{l}\text { R-Squared } \\
\text { Value }\end{array}$ & $\begin{array}{l}\text { Cronbach's } \alpha \\
\text { value }\end{array}$ & $\begin{array}{l}\text { C.R. } \\
\text { Value }\end{array}$ & $\begin{array}{l}\text { AVE } \\
\text { Value }\end{array}$ & Communality & $\begin{array}{l}\text { Factor } \\
\text { Loading }\end{array}$ \\
\hline \multirow{5}{*}{$\mathrm{CT}$} & CT1 & \multirow{5}{*}{4.2969} & \multirow{5}{*}{0.0000} & \multirow{5}{*}{0.8402} & \multirow{5}{*}{0.8857} & \multirow{5}{*}{0.6087} & \multirow{5}{*}{0.6087} & 0.7495 \\
\hline & CT 2 & & & & & & & 0.7065 \\
\hline & CT 3 & & & & & & & 0.8054 \\
\hline & CT 4 & & & & & & & 0.7991 \\
\hline & CT 5 & & & & & & & 0.8338 \\
\hline \multirow{6}{*}{ CRR } & CRR 1 & \multirow{6}{*}{4.3400} & \multirow{6}{*}{0.0000} & \multirow{6}{*}{0.8156} & \multirow{6}{*}{0.8678} & \multirow{6}{*}{0.5251} & \multirow{6}{*}{0.5251} & 0.7293 \\
\hline & CRR 2 & & & & & & & 0.8032 \\
\hline & CRR 3 & & & & & & & 0.7936 \\
\hline & CRR4 & & & & & & & 0.7557 \\
\hline & CRR 5 & & & & & & & 0.6269 \\
\hline & CRR 6 & & & & & & & 0.6161 \\
\hline \multirow{14}{*}{ TQS } & TQS 1 & \multirow{9}{*}{4.3402} & \multirow{9}{*}{0.5274} & \multirow{9}{*}{0.9085} & \multirow{9}{*}{0.9257} & \multirow{9}{*}{0.5836} & \multirow{9}{*}{0.5836} & 0.6634 \\
\hline & TQS 2 & & & & & & & 0.7881 \\
\hline & TQS 3 & & & & & & & 0.8343 \\
\hline & TOS 4 & & & & & & & 0.7555 \\
\hline & TQS 5 & & & & & & & 0.8710 \\
\hline & TQS 6 & & & & & & & 0.8412 \\
\hline & TQS 7 & & & & & & & 0.8010 \\
\hline & TQS8 & & & & & & & 0.6439 \\
\hline & TQS 9 & & & & & & & 0.6340 \\
\hline & CS 1 & \multirow{5}{*}{4.1061} & \multirow{5}{*}{0.2741} & \multirow{5}{*}{0.8464} & \multirow{5}{*}{0.8896} & \multirow{5}{*}{0.6184} & \multirow{5}{*}{0.6184} & 0.7599 \\
\hline & CS 2 & & & & & & & 0.8351 \\
\hline & CS 3 & & & & & & & 0.7995 \\
\hline & CS 4 & & & & & & & 0.8449 \\
\hline & CS 5 & & & & & & & 0.6810 \\
\hline
\end{tabular}

Note: CT= Condition of minibus taxis; CRR=Compliance with road rules; TQS= Total quality of service; CS= Commuter Satisfaction, C.R.: Composite Reliability; AVE: Average Variance Reliability.

* Scores: 1 - Strongly Disagree; 3 - Neutral; 5 - Strongly Agree

According to Chin (1998), research variables should have an average variance extracted (AVE) of more than 0.5 and a composite reliability of more than 0.7 (convergent validity), and inter-construct correlations should be less than the square-root of the AVE (discriminant validity). As can be seen in Table 2, all constructs exceed these criteria, with AVE and CR generally equal or greater than 0.5 and 0.8 , respectively, and the square-root of the AVE being at least 0.61 and greater than the inter-construct correlations in Table 3. All in all, these results confirm the existence of discriminant validity of the construct measurements used in this study.

Table 3: Correlations between Constructs

\begin{tabular}{|l|c|c|c|c|}
\hline \hline \multicolumn{1}{|c|}{ Research Constructs } & CRR & CS & CT & TQS \\
\hline Compliance with road rules (CRR) & 1.000 & & & \\
\hline Commuter Satisfaction (CS) & 0.6548 & 1.000 & & \\
\hline Condition of minibus taxis (CT) & 0.7023 & 0.8020 & 1.000 & \\
\hline Quality of Service (TQS) & 0.7167 & 0.5235 & 0.5865 & 1.000 \\
\hline \hline
\end{tabular}

Note: $\mathrm{CT}=$ Condition of minibus taxis; CRR=Compliance with road rules; TQS=Total quality of service; CS=Commuter Satisfaction 


\subsection{Structural model}

Figure 2 and Table 4 present the current study's hypothesis testing results of the PLS analysis. The standardized path coefficients are expected to be at least 0.2 , and preferably greater than 0.3 (Chin, 1998). Bootstrapping (300 re-samples) is utilised to assess the reliability of each coefficient. The results provide support for two out of three hypotheses ( $\mathrm{H} 2$ and $\mathrm{H} 3$ ) as $\mathrm{H} 1$ is not supported because of path coefficient of below $0.2(0.164)$. Thus, only two path coefficients for $\mathrm{H} 2$ and $\mathrm{H} 3$ are above 0.2 and significant (pb0.001). As indicated in Figure 2 and Table 4, the path coefficients are 0.164, 0.602 and 0.524 for $\mathrm{H} 1, \mathrm{H} 2$ and $\mathrm{H} 3$ respectively.

Figure 2: Measurement and Structural Model Results

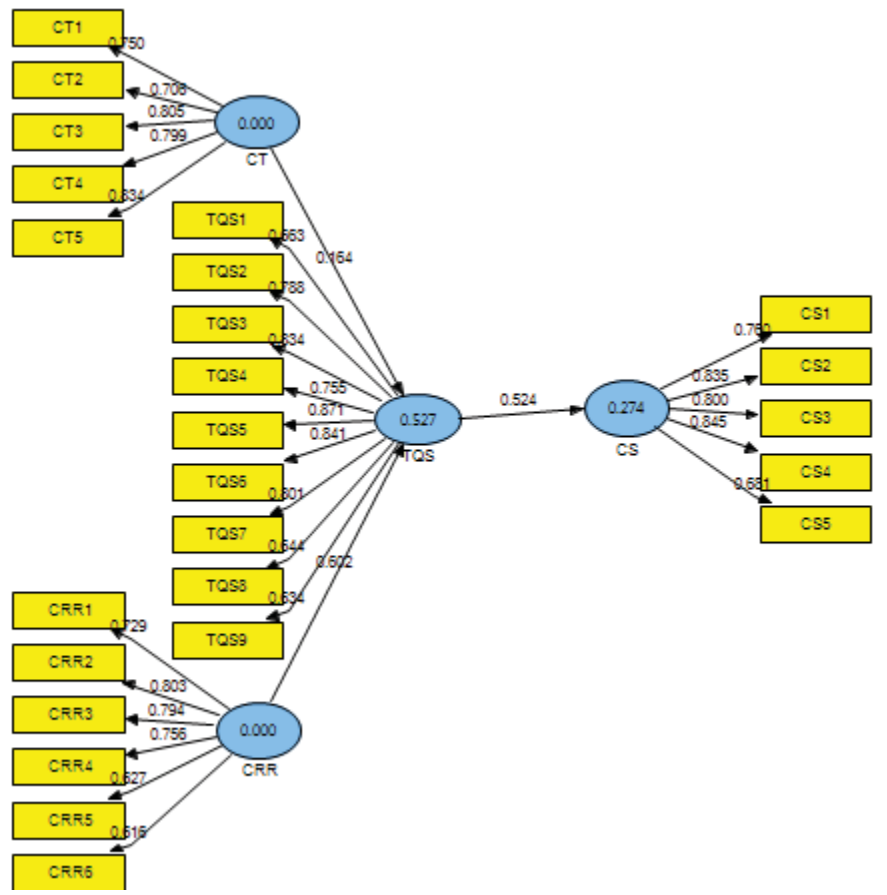

Note: CT=Condition of minibus Taxis; CRR=Compliance with road rules; TQS=Total quality of service; $C S=C o m m u t e r$ satisfaction

Table 4 provides the T-statistics for the hypothesised relationships in this study. The minimum T-statistics is 1.784 and therefore falls below the recommended threshold of 2. This disconfirms the statistical significance of the posited relationship between condition of omnibus taxis and the quality of services to commuters, the hypothesis is therefore not supported. The remaining two relationships exceeded the recommended threshold of 2 . This confirms the statistical significance of the posited relationships and therefore the hypotheses are supported.

Table 4: Results of Structural Equation Model Analysis

\section{Proposed Hypothesis Relationship}

\begin{tabular}{|c|c|c|c|} 
Hypothesis & Path Coefficients & T-Statistics & Rejected / Supported \\
\hline HI
\end{tabular}

Condition of minibus taxis (CT) $\rightarrow$ Quality of Service (TQS)

Compliance with road rules (CRR) $\rightarrow$ Quality of service (TQS) Quality of service (TQS) $\rightarrow$ Commuter Satisfaction (CS)

\begin{tabular}{l|c|c|c|} 
H1 & 0.164 & 1.784 & Not Supported \\
H2 & 0.602 & 6.30 & Supported \\
H5 & 0.524 & 6.097 & Supported \\
\hline
\end{tabular}

Note:CT= Condition of minibus taxis; TQS=Quality of service; CRR=Compliance with road rules; CS=Commuter satisfaction

Overall, $\mathrm{R}^{2}$ for quality of service and commuter satisfaction in Figure 2 is $52.7 \%$ and $27.4 \%$ respectively. This indicate that the research model explains more than $27.4 \%$ of the variance in the endogenous variables (commuter satisfaction) 
and $52.7 \%$ of quality of service. Following, the formulae provided by Tenenhaus, Vinzi, Chatelin and Lauro, (2005), the global goodness-of-fit (GoF) statistic for the research model was calculated and the GoF is 0.38 , which exceed the threshold of GoF>0.36 suggested by Wetzels, Odekerken-Schröder and van Oppen (2009). Thus, this study concludes that the research model has a good overall fit.

\section{Discussion and Conclusion}

The purpose of this study was to investigate the fostering role of condition of minibus taxis and compliance with road rules on quality of service and commuter satisfaction. In particular, three hypotheses were postulated. To test the proposed hypotheses, data was collected from commuters in Harrismith, South Africa. The empirical results supported two hypotheses $(\mathrm{H} 2$ and $\mathrm{H} 3)$ in a significant way and did not support $\mathrm{H} 1$.

When the effect of condition of omnibus taxis on service quality as perceived by commuters was considered in this study, the findings failed to support the posited positive relationship in a significant way. The reason for an insignificant effect of the condition of omnibus taxis on service quality could be that the condition of an omnibus taxi has an indirect effect on service quality perceived by commuters.

The impact of compliance with road rules on service quality to commuters was also considered, and a positive and significant impact was found. This confirms the general knowledge of compliance with rules yielding better service quality. Therefore, the compliance with road rules by taxi drivers enhances the perception of better service quality by commuters. Thus, this study concludes that compliance with road rules of omnibus taxi drivers in South Africa has a highly significant and positive impact on commuters' perception of service quality.

Lastly, this paper considered the effect of service quality on commuter satisfaction. The findings of this study reveal a stronger positive effect of service quality on commuter satisfaction. This is consistent with reasoning by Ramasubbu, Mithas and Krishnan (2008). Thus, the more commuters perceive service quality in omnibus taxis to be good, the more likely these commuters are to be satisfied with omnibus taxi services. Therefore, this study concludes that there is service quality of commuting omnibuses in South Africa has a positive effect on commuter satisfaction. Implicitly, these findings indicate that compliance with road rules can have a strong influence on commuter satisfaction via service quality. Perhaps this could be due to the fact that commuters are more concerned about their safety while in transit than the physical state of minibus taxis, hence they would expect the taxi drivers to comply with the road rules regardless of the condition of the taxi itself.

\subsection{Implications of the study}

The ever-increasing importance of the minibus taxi sector in Harrismith cannot be over-emphasised. In particular, the dependency of society on public transportation has often been cited in the empirical literature (Petzall, 1995). The current study is an attempt to undertake a research in an often most neglected context but yet an important sector of the Free State economy. Therefore, the findings of this empirical study are expected to provide fruitful implications to both practitioners and academicians.

On the practitioners' side, important influential role of service quality on commuter satisfaction in Harrismith's omnibus taxi sector is highlighted. This study therefore submits that taxi associations and omnibus taxi owners can benefit from the implications of these findings. For instance, given the robust relationship between service quality and commuter satisfaction (0.524), and compliance with road rules and service quality $(0.602)$ taxi associations in the minibus taxi sector and minibus taxi owners ought to pay attention to both compliance with road rules and service quality in order to optimise the satisfaction of commuters.

On the academic side, this study makes a significant contribution to the public transport literature by systematically exploring the impact of condition of minibus taxis and compliance with road rules on service quality and commuter satisfaction in the public transport context. Overall, the current study findings provide tentative support to the proposition that condition of minibus taxis, compliance with road rules; quality of service commuter satisfaction should be recognized as significant antecedents of commuter satisfaction in the public transport sector.

\subsection{Limitations and Future Research}

Despite the usefulness of this study aforementioned, the research has its limitations. First and most significantly, the present research was conducted from the perspective of commuters of minibus taxis only. Perhaps if data is collected 
from both the taxi drivers and the passengers; and a comparative study is done, insightful findings about the impact of condition of minibus taxis and compliance with road rules on quality of service and commuter satisfaction might be revealed. Second, the current study was limited to commuters of minibus taxis in Harrismith. Subsequent research should contemplate replicating this study in other South African provinces for results comparisons. Finally, further research could also investigate the effects of compliance of road rules on service quality as the outcome variable in the context of minibus taxi service sector. Such researches might potentially expand our understanding of the impact of compliance with road rules on commuter satisfaction, and eventually service quality. All in all, these suggested future avenues of study stand to immensely contribute new knowledge to the existing body of public transport literature, a context that is often most neglected by some researchers in developing countries (Chinomona and Pretorius, 2011).

\section{References}

Aberg L. 1998. Traffic rules and traffic safety. Safety Science, 29, 205-215.

Anderson JC, Gerbing DW. 1988. Structural equation modeling in practice: A review and recommended two step approach. Psychological Bulletin, 103, 411-423.

Bearden WO, Teel JE. 1983. Selected determinants of consumer satisfaction and complaint reports. Journal of Marketing Research, 20, 21-8.

Bjorklund GM, Aberg L. 2005. Driver behaviour in intersections: Formal and informal traffic rules. Transportation Research Part F 8, 239253.

Burns PC, Wilde GJS. 1995. Risk taking in male taxi drivers: Relationships among personality, observational data and driver records. Personality \& Individual Differences, 18, 267-278.

Cantwell M, Caulfield B, O'mahony M. 2009. Examining the factors that impact public transport commuting satisfaction. Journal of Public Transportation, 12(2), 1.

Chin WW. 1998. Issues and opinion on structural equation modelling, MIS Quarterly, 22 (1), 7-16.

Chin WW, Newsted PR. 199). Structural equation modeling analysis with small samples using partial least squares. In Rick Hoyle (Ed.), Statistical Strategies for Small Sample Research. Thousand Oaks, CA: Sage.

Chinomona R, Ming-Sung Cheng J. 2013. Distribution Channel Relational Cohesion Exchange Model: A Small-to-Medium Enterprise Manufacturer's Perspective.Journal of Small Business Management 51(2), pp. 256-275

Chinomona R, \& Sandada, M. 2013. Service Quality Level as the Determinant of Consumer Emotional Loyalty and Fantasy in South Africa's Pick \& Pay Chain Stores. Mediterranean Journal of Social Sciences, 4 (3): 579-586

Chinomona, R and Pretorius, M (2011), "SME manufacturers' Cooperation and Dependence On Major Dealers' Expert Power in Distribution Channels," South African Journal Of Economics and Management Sciences, 12 (2), 170-186

Eriksson L, Friman M, Garling T. 2013. Perceived attributes of bus and car mediating satisfaction with the work commute. Transportation Research Part A 47, 87-96.

Fernandez- Bremauntz AA, Ashmore MR. 1995. Exposure of commuters to carbon monoxide in Mexico City-l. Measurement of invehicle concentrations. Atmospheric Environment 29(4), 525-532.

Finn B. 2008. Market role and regulation of extensive urban minibus service as large bus service capacity is restored - case studies from Ghana, Georgia and Kazakhstan. Research in Transportation Economics 22, 118-125.

Fornell C, Johnson MD, Anderson EW, Cha J, Bryant BE. 1996. The American customer satisfaction index: Nature, purpose and findings. Journal of Marketing 60, 7-18.

Fornell C, Mithas S, Morgeson F, Krishnan MS. 2006. Customer satisfaction and stock prices: high returns, low risk. Journal of Marketing 70(1) 3-14.

Goodwin P, Lyons G. 2010. Public attitudes to transport: interpreting the evidence. Journal of Transportation Planning and Technology 33, 3-17.

Gronroos C. 1984. A service quality model and its marketing implications. European Journal of Marketing 18 (4), 36-44.

Lapierre J, Filiatrault P, Perrien J. 1996. Research on service quality evaluation: Evolution and methodological issues. Journal of Retailing and Consumer Services 3(2), 9-98.

Lucas K. 2011. Making the connections between transport disadvantage and the social exclusion of low income populations in the Tshwane Region of South Africa. Journal of Transport Geography 19, 1320-1334.

Naik CNK, Gantasala SB. 2010. Service quality (Servqual) and its effect of customer satisfaction in retailing. European Journal of Social Sciences 16 (2), 231-243.

Olio LD, Ibeas A, Cecin P. 2011. The quality of service desired by public transport users. Transport Policy 18, 217-227.

Olvera L, Plat D, Pochet P. 2003. Transportation conditions and access to services in a context of urban sprawl and deregulation. The case of Dar-es Salaam. Transport Policy 10, 287-298.

Paquette J, Cordeau JF, Laporte G. 2009. Quality of service in dial-a-ride operations. Computers \& Industrial Engineering 56, 17211734.

Prioni P, Hensher DA. 2000. Measuring service quality in scheduled bus services. Journal of Public Transport 3, 51-74.

Peltzer K, Renner W. 2003. Superstition, risk taking and risk perception of accidents among South African taxi drivers. Accident Analysis 
\& Prevention 35, 619-623.

Petzall J. 1995. The design of entrances of taxis for elderly and disabled passengers. Applied ergonomics 26 (5), 343-352.

Ramasubbu N, Mithas S, Krishnan MS. 2008. High tech, high touch: the effect of employee skills and customer heterogeneity on customer satisfaction with enterprise system support services. Decision Support Systems 44, 509-523.

Ringle, CM, Wende S, Will A. 2005. SmartPLS 2.0 M3. Available at http://www.smartpls.de

Redman L, Friman M, Garling T, Hartig T. 2013. Quality attributes of public transport that attract car users: A research review. Transport Policy 25, 119-127.

Rosenbloom T, Shahar A. 2007. Differences between taxi and non-professional male drivers in attitudes towards traffic-violation penalties. Transport Research Part F 10, 428-435.

Rothengatter T. 1991. Autocratic Policing and information systems for increasing traffic law compliance. Journal of Applied behaviour Analysis 24, 85-87.

Sekhonyane M, Dugard J. 2004. South African Crime Quarterly. No.10. http://www.iss.co.za

Tenenhaus M, Vinzi VE, Chatelin YM, Lauro C. 2005. PLS Path modeling. Computational Statistics \& Data Analysis 48 (1), $159-205$.

Tom A, Granier MA. 2011. Gender differences in pedestrian rule compliance and visual search at signalized and unsignalized crossroads. Accidents \& Analysis and Prevention 43, 1794-1804.

Tseng ML. 2009. Using the extension of DEMATEL to integrate hotel service quality perceptions into a cause - effect model in uncertainty. Expert Systems with Applications 36, 9015-9023.

Vazquez R, Bosque IAR, Diaz AM, Ruiz AV. 2001. Service quality in supermarket retailing: indentifying critical service experiences. Journal of Retailing and Consumer Services 8, 1-14.

Wener RE, Evans GW, Boately P. 2005. Commuting stress: psychological effects of a trip and spillover into the workplace. Transportation Research Record. Journal of Transportation Research Record 19, 112-117.

Wetzels M, Odekerken-Schröder G, Van Oppen C. 2009. Using PLS path modeling for assessing hierarchical construct models: Guidelines and empirical illustration. Management Information Systems Quarterly 33(1), 177-195.

Zhong S, Zhou L, Ma S, Jia N. 2012. Effects of different factors on drivers' guidance compliance behaviors under road condition information shown on VMS. Transportation Research Part A 46, 1490-1505. 